\title{
Expression of early growth response-1 in colorectal cancer and its relation to tumor cell proliferation and apoptosis
}

\author{
DAE-SEONG MYUNG $^{1 *}$, YOUNG-LAN PARK ${ }^{1 *}$, NURI KIM ${ }^{1}$, CHO-YUN CHUNG ${ }^{1}$, HYUNG-CHUL PARK $^{1}$, \\ JONG-SUN KIM $^{1}$, SUNG-BUM CHO ${ }^{1}$, WAN-SIK LEE ${ }^{1}$, JAE-HYUK LEE ${ }^{2}$ and YOUNG-EUN JOO ${ }^{1}$ \\ Departments of ${ }^{1}$ Internal Medicine and ${ }^{2}$ Pathology, Chonnam National University \\ Medical School, Gwangju, Republic of Korea
}

Received August 13, 2013; Accepted October 2, 2013

DOI: $10.3892 /$ or.2013.2884

\begin{abstract}
Early growth response-1 (Egr-1) is implicated in the regulation of cell growth, proliferation, differentiation and apoptosis. Egr-1 is considered tobe either a tumor-suppressor or tumor-promoter, depending on the cell type and environment. The aim of the present study was to evaluate the expression of Egr-1 in colorectal cancer and its correlation with tumor cell proliferation, apoptosis and clinicopathological features. The expression of Egr-1 in colorectal cancer tissues was investigated by reverse transcription-polymerase chain reaction (RT-PCR), western blotting and immunohistochemistry. Apoptosis was detected by terminal deoxynucleotidyl transferase (TdT)mediated deoxyuridine triphosphate (dUTP) nick end labeling (TUNEL), and cellular proliferative activity was evaluated by immunohistochemical staining with the Ki-67 antibody. Egr-1 expression was significantly elevated in colorectal cancer tissues, when compared to that in the paired normal mucosa at the mRNA and protein levels. In addition, Egr-1 expression was significantly increased in the metastatic lymph node tissues, when compared to that in the non-metastatic lymph node tissues at the protein level. The mean Ki-67 labeling index (KI) and apoptotic index (AI) values for 158 tumors were 53.6 \pm 15.4 and $9.0 \pm 1.0$, respectively. Higher KI values were significantly associated with distant metastasis. Lower
\end{abstract}

Correspondence to: Professor Young-Eun Joo, Department of Internal Medicine, Chonnam National University Medical School, 8 Hak-Dong, Dong-ku, Gwangju 501-757, Republic of Korea

E-mail: yejoo@chonnam.ac.kr

${ }^{*}$ Contributed equally

Abbreviations: Egr-1, early growth response-1; AJCC, American Joint Committee on Cancer; RT-PCR, reverse transcriptionpolymerase chain reaction; MMLV, molony-murine leukemia virus; KI, Ki-67 labeling index; TUNEL, terminal deoxynucleotidyl transferase (TdT)-mediated deoxyuridine triphosphate (dUTP) nick end labeling; AI, apoptotic index

Key words: early growth response-1, colorectal neoplasm, cell proliferation, apoptosis
AI values were significantly associated with lymph node metastasis. However, KI or AI values were not associated with patient survival. The mean KI value of Egr-1-positive tumors was significantly higher than that of Egr-1-negative tumors. However, there was no significant difference between Egr-1 expression and AI value. Positive expression of Egr-1 was significantly associated with age, lymphovascular invasion, lymph node and distant metastasis, tumor stage and poor survival. These results indicate that Egr-1 may be associated with colorectal cancer progression via tumor cell proliferation.

\section{Introduction}

Cell proliferation and apoptosis must be properly balanced in order to support proper development and maintain healthy homeostasis of mature tissues (1). A highly regulated process to control this balance involves each cell receiving survival signals from its microenvironment and from external stimuli (1).

Cancer cells are characterized by their ability to proliferate in an uncontrolled manner in contrast to normal cells, in which the proliferation is tightly regulated (2). In addition, apoptosis is a continuous physiologic process in tissue homoeostasis, and functions as a defense against pathogens and helps with the elimination of unwanted cells (3-5). Dysregulated apoptosis can lead to extended aberrant cell viability or may favor the accumulation of transforming mutations, and it is thought to contribute to carcinogenesis (3-5). Therefore, tumor development and progression are generally regarded as dependent on an increased proliferation rate and an apoptosis rate too low to balance cell growth.

Early growth response-1 (Egr-1) is a Cys2-His2-type zinc-finger transcription factor that is rapidly induced in response to a broad range of extracellular stimuli and plays a critical role in controlling cell growth, proliferation, differentiation and apoptosis (6-12). Interestingly, Egr-1 is considered to be either a tumor-suppressor or tumor-promoter, depending on cell type and external stimuli. The growth suppressing activity of Egr-1 has been observed in certain human cancers such as fibrosarcoma, glioblastoma, lung and breast cancer (13-16). In contrast, Egr-1 has been found to promote tumor cell growth in certain human cancer tissues such as prostate, skin and kidney cancers, in which Egr-1 is found at 
elevated levels (17-19). In particular, Egr-1 expression is associated with higher Gleason scores and poor differentiation in human prostatic cancer (20). Accumulating evidence suggests that Egr-1 is involved in the development and progression of human cancers, particularly as a tumor promoter.

Previously, Egr-1 was found to promote tumor cell growth and inhibit apoptosis in human colon cancer cells (21-23). Therefore, Egr-1 expression is believed to be involved in tumor development and progression by affecting cell proliferation and apoptosis in human colorectal cancer. However, there are no data concerning the impact of Egr-1 on tumor cell proliferation and apoptosis in human colorectal cancer tissues.

The aim of the present study was to evaluate the expression of Egr-1 in human colorectal cancer and its correlation with tumor cell proliferation, apoptosis and clinicopathological features including patient survival.

\section{Materials and methods}

Patient and sample selection. The mRNA and protein expression of Egr-1 was evaluated in human colorectal cancer tissues, paired normal colorectal mucosa, metastatic or non-metastatic lymph node tissues of the same patients from colonoscopic biopsies and surgical specimens. For immunohistochemical staining, formalin-fixed and paraffin-embedded tumor specimens from 158 randomly chosen patients who had undergone surgery for colorectal cancer at Chonnam National University, Hwasun Hospital (Jeonnnam, Korea) between July 2004 and June 2005 were studied. None of the patients had received preoperative radiotherapy or chemotherapy. Pathological reports and clinical histories at the time of surgery were reviewed through the medical records. Tumor staging was in accordance with the American Joint Committee on Cancer (AJCC) staging system (24). Survival was measured from the time of surgery until follow-up in December 2010. The study group comprised 94 males and 64 females. The median age was $66.3 \pm 12.3$ (means \pm SD) with a range of 26-90 years. The mean size of the tumors was $5.1 \pm 2.3 \mathrm{~cm}$ (means \pm SD) with a range of $1.5-14.0 \mathrm{~cm}$. The mean follow-up period was 43.1 months with a range of 0.7-56.0 months. This study was approved by the Institutional Review Board of Chonnam National University, Hwasun Hospital. Written informed consent was obtained from each participant prior to tissue acquisition. All participants provided written consent for their information to be stored in the hospital database and used for research.

Reverse transcription-polymerase chain reaction (RT-PCR). Total RNA was extracted from cells in $1 \mathrm{ml}$ of TRIzol reagent (Invitrogen Life Technologies, Carlsbad, CA, USA) according to the manufacturer's protocol and subjected to reverse transcriptase polymerase-chain reaction (PCR). For cDNA synthesis, $1 \mu \mathrm{g}$ of RNA was reverse transcribed with Molony-murine leukemia virus (MMLV) transcription reagents (Invitrogen Life Technologies). PCR amplification of cDNA was performed using genespecific primers and Go Taq ${ }^{\circledR}$ DNA polymerase (Promega Corporation, Madison, WI, USA). The following primers were used; Egr-1, 5'-CAGTGGCCTAGTGAGCATGA-3' and 5'-CCGCAAGTGGATCTTGGTAT-3'; GAPDH, 5'-ACC ACA

\section{GTC CAT GCC ATC AC-3'/5'-TCC ACC ACC CTG TTG CTG TA-3'.}

Western blotting. Total cell extracts were prepared in RIPA buffer using the Halt ${ }^{\mathrm{TM}}$ protease and phosphatase inhibitor cocktail (both from Thermo Scientific Rockford, IL, USA). Cells were disrupted by sonication and centrifuged at $4^{\circ} \mathrm{C}$. Equal amounts of protein were separated on polyacrylamide gels, and transferred to PVDF membranes (Millipore, Billerica, MA, USA). Blots were blocked with 5\% milk and incubated with primary antibodies against Egr-1 (Santa Cruz Biotechnology, Inc., Santa Cruz, CA, USA). Immunoreactive proteins were visualized by the enhanced chemiluminescence detection system HRP substrate (Millipore). Immunoreactive protein bands were quantified using the luminescent image analyzer LAS-4000 and MultiGauge V3.2 image analyzer software (Fujifilm, Tokyo, Japan).

Immunohistochemistry. Formalin-fixed and paraffinembedded tissue sections $(4 \mu \mathrm{m})$ with mounted probe on slides, were immunostained with anti-rabbit polyclonal antibody for the Egr-1 antigen (R\&D Systems, Inc.) using the avidin-biotin peroxidase complex method. Sections were deparaffinized and heated in a microwave oven for $7 \mathrm{~min}$ to retrieve the antigens. They were immersed in $0.6 \%$ hydrogen peroxide for $10 \mathrm{~min}$ to block the endogenous peroxidase activity. The primary antibody, at a concentration of 1:100, was diluted in phosphate-buffered saline supplemented with $5 \%$ normal horse serum and $1 \%$ bovine serum albumin and then incubated with tissues overnight at room temperature. Anti-mouse immunoglobulin G (Sigma, St. Louis, MO, USA) labeled with biotin was used as a secondary antibody for the detection of primary antibodies and was incubated for $10 \mathrm{~min}$ at $45^{\circ} \mathrm{C}$. After multiple rinses with universal buffer, the streptavidin-alkaline phosphatase detection system (Biomeda, Foster City, CA, USA) was applied for $8 \mathrm{~min}$. As the final step, the slides were developed for $10 \mathrm{~min}$ with the enzyme substrate, 3,3-diaminobenzidine (Sigma). The slides were counterstained with hematoxylin solution for $3 \mathrm{~min}$ (Research Genetics, Huntsville, AL, USA). After dehydration, the tissue was sealed with a universal mount (Research Genetics). For negative controls, the primary antibody was omitted and replaced with phosphate-buffered saline.

Assessment of Egr-1 expression. The immunoreactivity was evaluated independently by 2 observers without knowledge of the clinical outcomes, through analysis of intensity, area and pattern of immunostaining. Staining intensity was classified from 0 (no staining) to 3 (strong staining), and the percentage of the staining area was classified as 0 for no positive staining of tumor cells, 1 for positive staining in $<10 \%$ of the tumor cells, 2 for positive staining in $10-50 \%$ of the tumor cells, or 3 for positive staining in $>50 \%$ of the tumor cells. The staining index was calculated as the product of staining intensity and staining area. Assessment of the staining was evaluated by 2 independent pathologists without knowledge of the clinical outcomes such as tumor stage, grade and survival. Consensus scores were assigned for each case by reviewing the slides with discrepancies in scoring. All sections for which there was disagreement between the 2 observers were re-evaluated 
and discussed. There was total agreement on the classification. The tumors were categorized as having positive expression (staining index $\geq 4$ ) or negative expression (staining index $<4$ ).

Assessment of tumor cell proliferation. Immunohistochemical staining with the polyclonal Ki-67 antibody (MIB-1; diluted 1:150; Dakopatts, Glostrup, Denmark) using the avidin-biotin peroxidase complex method and 3,3-diaminobenzidine (Sigma) as chromogen was performed. A distinct brown staining of the nuclei with strong intratumoral heterogeneity was considered $\mathrm{Ki}$-67-positive. The Ki-67-positive tumor cells were evaluated with a light microscope holding a x100 oil immersion objective by scoring a minimum of 1,000 tumor cells in randomly selected fields. For each case, 3 different counts were performed, and the highest score was chosen as the corresponding index. The Ki-67 labeling index (KI) was presented as the number of $\mathrm{Ki}$-67-positive nuclei/1,000 tumor cell nuclei.

Detection of apoptotic cells and bodies. For detection of apoptotic cells, sections of formalin-fixed and paraffin-embedded tissue were processed for in situ immunohistochemical localization of nuclei exhibiting DNA fragmentation, by the terminal deoxynucleotidyl transferase (TdT)-mediated deoxyuridine triphosphate (dUTP) nick end labeling (TUNEL) method, using the ApopTag ${ }^{\mathrm{TM}}$ Plus In situ Apoptosis Detection kit (Intergen, Purchase, NY, USA). Sections were treated according to the manufacturer's instructions as previously described (25). Briefly, sections were deparaffinized and rehydrated with xylene and ethanol, and permeabilized with $20 \mu \mathrm{g} / \mathrm{ml}$ proteinase $\mathrm{K}$ (Sigma) for $15 \mathrm{~min}$ at room temperature. Endogenous peroxidase was inactivated by coating the samples with $2 \%$ hydrogen peroxide $\left(\mathrm{H}_{2} \mathrm{O}_{2}\right)$. Sections were rinsed with phosphate-buffered saline, and then immersed for $120 \mathrm{~min}$ in TdT buffer at $37^{\circ} \mathrm{C}$. Afterwards, they were incubated for $60 \mathrm{~min}$ with the anti-digoxygenin peroxidase-conjugate, followed by the peroxidase substrate diaminobenzidine. Finally, sections were counterstained with Mayer's hematoxylin. The positive control sections were treated with $0.7 \mathrm{~g} / \mathrm{ml}$ DNase I (Sigma) in potassium cacodylate buffer ( $\mathrm{pH}$ 7.2) for $10 \mathrm{~min}$ before treatment with TdT buffer. As a negative control, a number of tissue samples were subjected to treatment without TdT. The percentage of apoptotic cells was determined by counting labeled cells at a $\times 400$ magnification in randomly selected and homogeneous fields. Apoptotic cells were also identified by their characteristic morphological features in hematoxylin and eosin-stained sections such as cell shrinkage and chromatin margination or chromatin condensation with formation of apoptotic bodies (25). The apoptotic index (AI) was expressed as the number of positive nuclei including apoptotic bodies among 1,000 tumor cell nuclei.

Statistical analysis. All statistical analyses were carried out using the Statistical Package for the Social Sciences (SPSS/PC Plus Professional Statistics 15.0; SPSS, Inc., Chicago, IL, USA). The correlation between Egr-1 expression and the clinicopathological parameters was examined by $\chi^{2}$ test and Fisher's exact test. The relationship between Egr-1 expression and KI or AI was evaluated by the Student's t-test. Survival curves were calculated according to the Kaplan-Meier method,
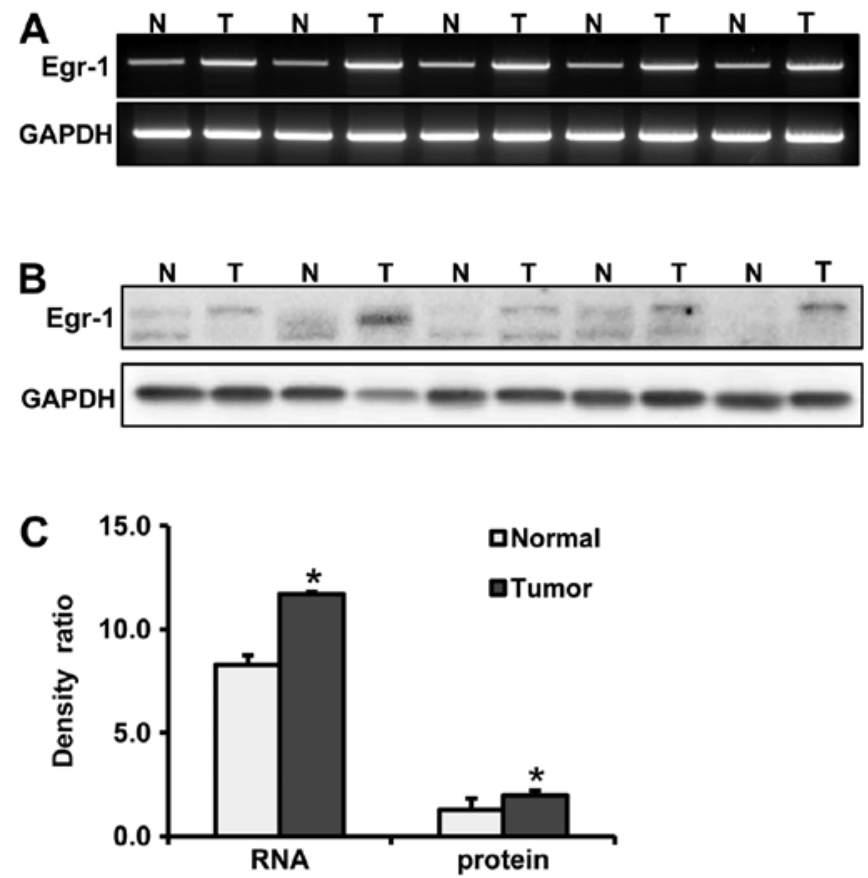

Figure 1. Expression of Egr-1 in human colorectal cancer tissues by reverse transcriptase-polymerase chain reaction (RT-PCR) and western blotting. (A) Egr-1 mRNA expression by RT-PCR. (B) Egr-1 protein expression by western blotting. T, colorectal cancer tissue; $\mathrm{N}$, paired normal colorectal mucosa. (C) Expression of Egr-1 was significantly higher in the human colorectal cancer tissue than that in the normal colorectal mucosa at the mRNA and protein levels. Each bar of the histogram represents the means \pm SE of 20 cases. " $p<0.01$ vs. normal gastric mucosa. Egr-1, early growth response-1.

and the differences were tested with a log-rank test. A p-value of $<0.05$ was considered to indicate a statistically significant result.

\section{Results}

Expression of Egr-1 in human colorectal cancer and metastatic lymph node tissues. We evaluated the expression of Egr-1 at the mRNA and protein levels by RT-PCR, western blotting and immunohistochemistry in human colorectal cancer tissues, paired normal colorectal mucosa, and metastatic or non-metastatic lymph node tissues of the same patients taken by colonoscopic biopsy and as surgical specimens. In the colonoscopic biopsy specimens, we confirmed upregulation of Egr-1 expression at both the mRNA and protein levels in cancer tissues when compared to levels in the paired normal mucosa $(\mathrm{p}=0.002$ and $\mathrm{p}=0.046$, respectively) (Fig. 1). In the paraffin tissue sections, immunostaining of Egr-1 protein in the normal colorectal mucosa was absent or weak (Fig. 2A). The immunostaining of Egr-1 protein was predominantly identified in the cytoplasm of cancer cells and was not detectable in the tumor stromal (Fig. 2A). The immunostaining of Egr-1 in metastatic lymph node tissues was significantly stronger than that in the non-metastatic lymph node tissues (Fig. 2B). The overall score for immunostaining of Egr-1 in the metastatic lymph node tissues was significantly higher than that in the non-metastatic lymph node tissues ( $<<0.001)$ (Fig. 2C). 

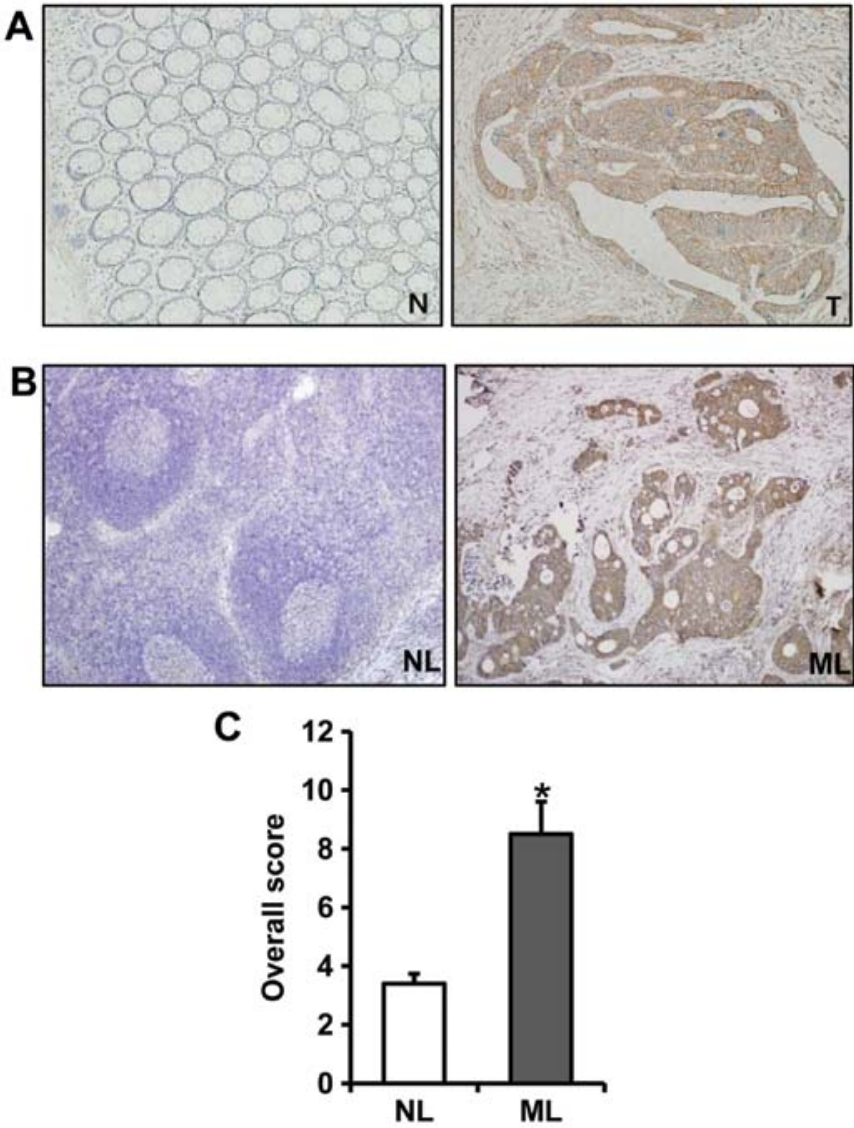

Figure 2. Expression of Egr-1 protein in human colon cancer and metastatic lymph node tissues by immunohistochemistry. (A) Immunostaining of Egr-1 protein was predominantly identified in the cytoplasm of tumor cells, and immunostaining was absent or weak in normal colorectal mucosa. T, colorectal cancer tissue; $\mathrm{N}$, paired normal colorectal mucosa. (B) Immunostaining of Egr-1 protein in the metastatic lymph node tissues was significantly stronger than that in the non-metastatic lymph node tissues. Original magnification, $x 200$. (C) The overall score of immunostaining of Egr-1 in the metastatic lymph node tissues was significantly higher than that in the non-metastatic lymph node tissues. Each bar of the histogram represents the means \pm SE of 20 cases. "p $<0.05$ vs. non-metastatic lymph node tissue. NL, non-metastatic lymph node tissue; ML, metastatic lymph node tissue. Egr-1, early growth response-1.

Expression of Ki-67 protein and detection of apoptosis in tissue specimens. Ki-67 immunoreactivity was found in the nuclei of cancer cells (Fig. 3A). Positive cells were commonly observed in the advancing margin of the tumors. The standard morphologic criteria of apoptotic cells using the TUNEL method include cell shrinkage and chromatin margination or chromatin condensation with formation of apoptotic bodies. Almost all of the positively stained cells and bodies were considered to be apoptotic cells as they corresponded morphologically to the standard criteria of apoptotic cells (Fig. 3B). Nonspecific staining in necrotic foci showed a faint and diffuse staining and it was distinguished from apoptotic nuclei by simple morphological examination.

Correlation between the expression of Egr-1 protein and clinicopathological features. The correlation between Egr-1 protein expression and clinicopathological parameters is shown in Table I. Positive expression of Egr-1 was significantly associated with age, lymphovascular invasion, lymph node
A

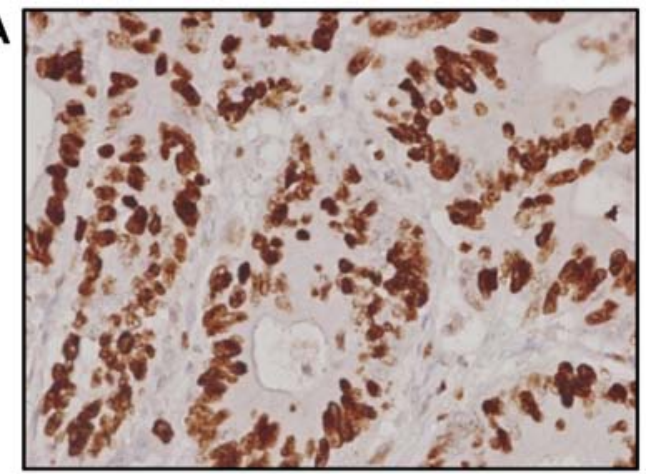

B

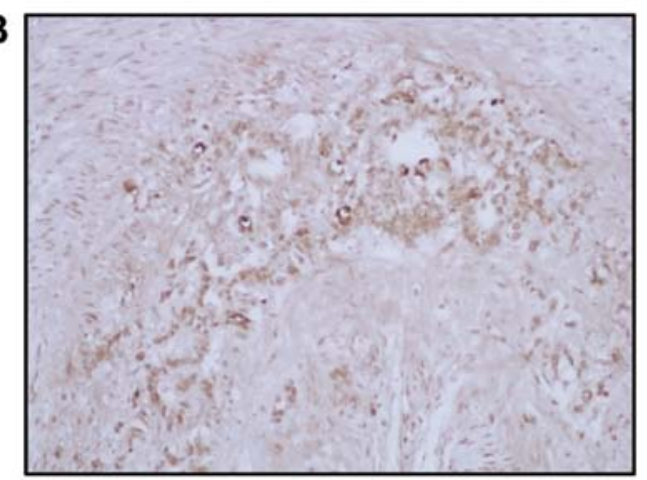

Figure 3. Detection of tumor cell proliferation and apoptosis in human colorectal cancer tissues. (A) Immunostaining of Ki-67 in colorectal cancer tissue. Ki-67 immunoreactivity was found in the nuclei of cancer cells (x200). (B) Detection of apoptotic cells and bodies by the TUNEL method. An apoptotic body characterized by a pyknotic nucleus surrounded by shrunken cytoplasm and separated from the surrounding cells by a halo (x400).

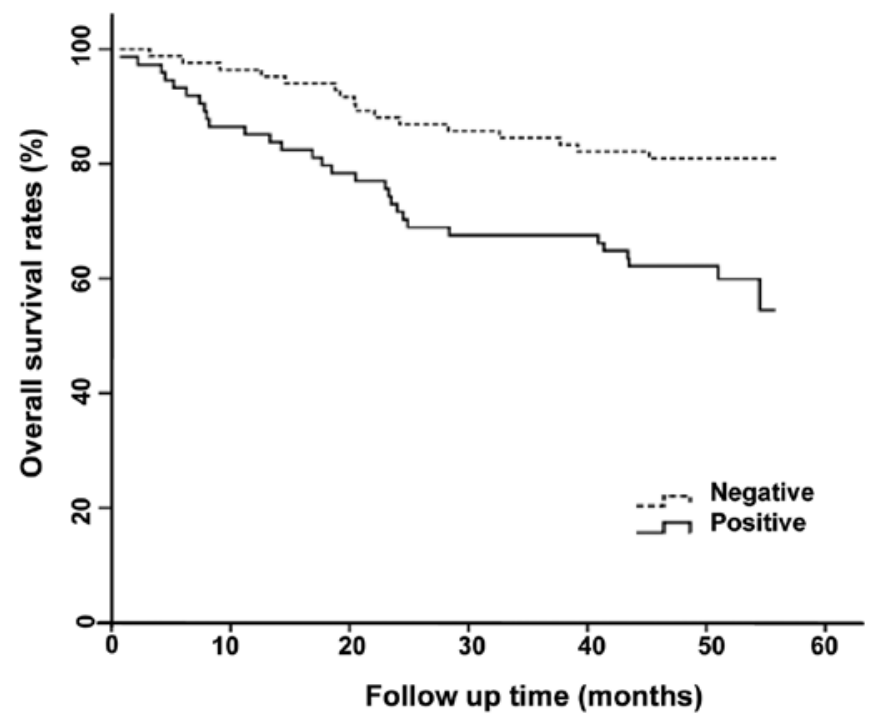

Figure 4. Kaplan-Meier survival curve correlating overall survival with positive expression (solid line) and negative expression (dotted line) of Egr-1 $(\mathrm{p}=0.007)$. Egr-1, early growth response-1.

and distant metastasis and tumor stage $(\mathrm{p}=0.023, \mathrm{p}=0.024$, $\mathrm{p}<0.001, \mathrm{p}<0.001$ and $\mathrm{p}<0.001$, respectively). Furthermore, positive expression of Egr-1 was associated with poor survival ( $\mathrm{p}=0.007$ ) (Fig. 4). 
Table I. Correlation between Egr-1 protein expression and clinicopathological parameters of the human colorectal cancer cases.

\begin{tabular}{|c|c|c|c|c|}
\hline \multirow[b]{2}{*}{ Parameters } & \multirow[b]{2}{*}{$\begin{array}{c}\text { Total } \\
(\mathrm{n}=158)\end{array}$} & \multicolumn{2}{|c|}{ Egr-1 } & \multirow[b]{2}{*}{ P-value } \\
\hline & & $\begin{array}{l}\text { Negative } \\
(n=84)\end{array}$ & $\begin{array}{l}\text { Positive } \\
(n=74)\end{array}$ & \\
\hline Age (years) & & & & 0.023 \\
\hline$<67$ & 62 & 26 & 36 & \\
\hline$\geq 67$ & 96 & 58 & 38 & \\
\hline Gender & & & & 0.334 \\
\hline Male & 94 & 47 & 47 & \\
\hline Female & 64 & 37 & 27 & \\
\hline Tumor size (cm) & & & & 0.186 \\
\hline$<5.0$ & 92 & 53 & 39 & \\
\hline$\geq 5.0$ & 66 & 31 & 35 & \\
\hline Stage & & & & $<0.001$ \\
\hline $\mathrm{I} / \mathrm{II}$ & 78 & 62 & 16 & \\
\hline III/IV & 80 & 22 & 58 & \\
\hline Lymphovascular invasion & & & & 0.024 \\
\hline Negative & 100 & 60 & 40 & \\
\hline Positive & 58 & 24 & 34 & \\
\hline Histological type & & & & 0.811 \\
\hline Well differentiated & 93 & 51 & 42 & \\
\hline Moderately differentiated & 45 & 24 & 21 & \\
\hline Poorly differentiated & 7 & 3 & 4 & \\
\hline Mucinous & 12 & 6 & 6 & \\
\hline Signet & 1 & 0 & 1 & \\
\hline Depth of invasion (T) & & & & 0.324 \\
\hline $\mathrm{T} 1 / \mathrm{T} 2$ & 26 & 17 & 9 & \\
\hline $\mathrm{T} 3 / \mathrm{T} 4$ & 132 & 67 & 65 & \\
\hline Lymph node metastasis $(\mathrm{N})$ & & & & $<0.001$ \\
\hline No & 80 & 62 & 18 & \\
\hline $\mathrm{N} 1-3$ & 78 & 22 & 56 & \\
\hline Distant metastasis (M) & & & & $<0.001$ \\
\hline M0 & 148 & 84 & 64 & \\
\hline M1 & 10 & 0 & 10 & \\
\hline
\end{tabular}

Egr-1, early growth response-1.

Correlation between the expression of Egr-1 protein and tumor cell proliferation or apoptosis. The Ki-67 labeling index (KI) for 158 tumors ranged from 21.9 to 85.7 with a mean KI of 53.6 \pm 15.4 . The mean KI value of Egr-1-positive tumors was $60.1 \pm 14.9$ which was significantly higher than that of the Egr-1-negative tumors ( $p=0.031)$ (Table II). The apoptotic index (AI) for 158 tumors ranged from 0.9 to 30.0 with a mean AI of $9.0 \pm 1.0$. However, there was no significant difference between Egr-1 expression and AI ( $\mathrm{p}=0.357)$ (Table III).

Correlation between KI or AI and clinicopathological features. The correlation between KI or AI and clinicopatho-
Table II. Correlation between KI and the status of Egr-1 protein expression in human colorectal cancer.

\begin{tabular}{lccc}
\hline $\begin{array}{l}\text { Egr-1 protein } \\
\text { expression }\end{array}$ & $\begin{array}{c}\text { Total } \\
(\mathrm{n}=158)\end{array}$ & $\begin{array}{c}\text { KI } \\
(\text { means } \pm \text { SD })\end{array}$ & P-value \\
\hline Negative & 84 & $49.1 \pm 14.7$ & 0.031 \\
Positive & 74 & $60.1 \pm 14.9$ & \\
\hline
\end{tabular}

KI, Ki-67 labeling index; Egr-1, early growth response-1; SD, standard deviation.

Table III. Correlation between AI and the status of Egr-1 protein expression in human colorectal cancer.

\begin{tabular}{lccc}
\hline $\begin{array}{l}\text { Egr-1 protein } \\
\text { expression }\end{array}$ & $\begin{array}{c}\text { Total } \\
(\mathrm{n}=158)\end{array}$ & $\begin{array}{c}\mathrm{AI} \\
(\text { means } \pm \mathrm{SD})\end{array}$ & P-value \\
\hline Negative & 84 & $10.2 \pm 6.3$ & 0.357 \\
Positive & 74 & $8.4 \pm 4.6$ & \\
\hline
\end{tabular}

AI, apoptotic index; Egr-1, early growth response-1; SD, standard deviation.

logical parameters associated with Egr-1 expression is shown in Table IV. The mean KI value of the positive distant metastatic tumors was $64.2 \pm 13.7$ which was significantly higher than that of the negative tumors $(\mathrm{p}=0.042)$. The mean AI value of the negative lymph node metastatic tumors was $11.5 \pm 7.1$ and was significantly higher than that of the positive tumors $(p=0.024)$. However, there was no association between KI or AI and age, tumor stage or lymphovascular invasion. In addition, KI or AI was not associated with patient survival (data not shown).

\section{Discussion}

Egr-1 is a member of the zinc-finger transcription factor family that is rapidly and transiently induced by a number of external stimuli including growth factors, cytokines and radiation injury. It regulates a wide spectrum of biological processes including cell growth, proliferation, apoptosis, cell cycle arrest, senescence, differentiation and cancer progression (6-12). Notably, Egr-1 expression has been found to be elevated in human prostatic (20) and gastric cancer tissues $(26,27)$ and it has been suggested that Egr-1 plays an important role in carcinogenesis and cancer progression in the prostate and stomach $(20,26,27)$. Our study showed that expression of Egr-1 mRNA and protein was increased in colorectal cancer tissue when compared with the barely detectable levels that were present in the matched normal colorectal mucosa. This result suggests that Egr-1 expression is implicated in colorectal carcinogenesis.

Although Egr-1 is considered to be a tumor-suppressor gene in several types of cancers (13-16), Egr-1 expression has been reported to be associated with cancer progression in prostatic and gastric cancers $(20,26,27)$. In our study, increased expression of Egr-1 was significantly associated with age, 
Table IV. Correlation between KI or AI and clinicopathological parameters of the human colorectal cancer cases.

\begin{tabular}{|c|c|c|c|c|c|}
\hline Parameters & Total $(n=158)$ & $\mathrm{KI}($ means $\pm \mathrm{SD})$ & $\mathrm{P}$-value & $\mathrm{AI}($ means $\pm \mathrm{SD})$ & P-value \\
\hline Age (years) & & & 0.586 & & 0.431 \\
\hline$<67$ & 62 & $51.7 \pm 18.30$ & & $8.1 \pm 4.27$ & \\
\hline$\geq 67$ & 96 & $55.0 \pm 13.85$ & & $9.7 \pm 6.68$ & \\
\hline Stage & & & 0.138 & & 0.134 \\
\hline $\mathrm{I} / \mathrm{II}$ & 78 & $55.7 \pm 14.73$ & & $12.5 \pm 6.3$ & \\
\hline III/IV & 80 & $56.7 \pm 15.31$ & & $7.6 \pm 3.60$ & \\
\hline Lymphovascular invasion & & & 0.256 & & 0.332 \\
\hline Negative & 100 & $49.1 \pm 19.00$ & & $9.2 \pm 5.44$ & \\
\hline Positive & 58 & $55.8 \pm 14.33$ & & $7.4 \pm 6.53$ & \\
\hline Lymph node metastasis $(\mathrm{N})$ & & & 0.715 & & 0.024 \\
\hline No & 80 & $54.5 \pm 13.59$ & & $11.5 \pm 7.09$ & \\
\hline $\mathrm{N} 1-3$ & 78 & $52.6 \pm 17.15$ & & $7.3 \pm 4.01$ & \\
\hline Distant metastasis (M) & & & 0.042 & & 0.753 \\
\hline M0 & 148 & $49.9 \pm 13.96$ & & $9.3 \pm 6.20$ & \\
\hline M1 & 10 & $64.2 \pm 13.73$ & & $8.4 \pm 2.90$ & \\
\hline
\end{tabular}

KI, Ki-67 labeling index; AI, apoptotic index; SD, standard deviation.

lymphovascular invasion, lymph node and distant metastasis, tumor stage and poor survival. Moreover, Egr-1 expression at the protein level was significantly increased in metastatic lymph node tissues, when compared to that in the non-metastatic lymph node tissues. These results strongly suggest that Egr-1 is involved in colorectal cancer progression and may have prognostic significance for colorectal cancer patients.

The continuous balance between cell proliferation and apoptosis is essential for the optimal function of nearly all tissues and organ systems, and must be properly coordinated. However, if cell proliferation exceeds apoptosis, neoplastic diseases and cancer may occur. Previous studies have shown that Egr-1 is involved in tumor development and progression by promotion of tumor cell growth and inhibition of apoptosis in human colon cancer cells (21-23). Therefore, we investigated the impact of Egr-1 on cell proliferation and apoptosis in colorectal cancer tissues.

$\mathrm{Ki}-67$ is a nuclear antigen that is expressed in all stages of the cell cycle except for G0 and early G1, and it is an established proliferation marker and has been extensively used to estimate the growth fraction of tumors $(28,29)$. Previous reports showed that $\mathrm{Ki}-67$ expression was associated with tumor progression and patient survival in various human cancers including colorectal cancer (30-32). Recently, Egr-1 was found to promote tumor cell proliferation in gastric cancer cells (33). In the present study, higher KI values were significantly associated with distant metastasis, and the mean KI value of Egr-1-positive tumors was significantly higher than that of Egr-1-negative tumors. These results suggest that Egr-1 may be involved in tumor development and progression of colorectal cancer by affecting tumor cell proliferation.

The TUNEL method has been designed to detect apoptotic cells that undergo extensive DNA degradation during the late stages of apoptosis $(25,34,35)$. Previously, apoptosis-related genes have been identified as independent prognostic factor, and they have proven to be useful therapeutic targets in cancer therapy (36-38). Egr-1 did exert an effect as an inhibitor of the apoptotic pathway in colorectal cancer cells (23). In our study, a lower AI value was significantly associated with lymph node metastasis, but the AI value did not correlate with patient survival. Furthermore, no significant difference was noted between Egr-1 expression and AI in colorectal cancer tissues. These results suggest that the steps in apoptosis are not dependent on Egr-1 alone, and are controlled by numerous regulators including pro-apoptotic and anti-apoptotic genes (3-5).

In summary, Egr-1 expression was significantly elevated in colorectal cancer tissues, when compared to that in paired normal mucosa. In addition, Egr-1 expression was significantly increased in metastatic lymph node tissues, when compared to that in non-metastatic lymph node tissues. Increased expression of Egr-1 was significantly associated with age, lymphovascular invasion, lymph node and distant metastasis, tumor stage and poor survival. KI was significantly associated with distant metastasis. The mean KI value of Egr-1-positive tumors was significantly higher than that of Egr-1-negative tumors. However, there was no significant difference between Egr-1 expression and the AI value. These results indicate that Egr-1 may be associated with colorectal cancer progression via tumor cell proliferation.

\section{Acknowledgements}

This study was supported by a grant (0720570) from the National R\&D Program for Cancer Control, Ministry of Health and Welfare, Republic of Korea, and partly by a research funds for the Research Institute of Clinical Medicine, Chonnam National University Hospital in 2012 (CRI 12035-1), Republic of Korea. 


\section{References}

1. Raff MC: Social controls on cell survival and cell death Nature 356: 397-400, 1992

2. DeBerardinis RJ, Lum JJ, Hatzivassiliou G and Thompson CB The biology of cancer: metabolic reprogramming fuels cell growth and proliferation. Cell Metab 7: 11- 20, 2008.

3. Schultz DR and Harrington WJ Jr: Apoptosis: programmed cell death at a molecular level. Semin Arthritis Rheum 32: 345-369, 2003.

4. Thompson CB: Apoptosis in the pathogenesis and treatment of disease. Science 267: 1456-1462, 1995.

5. Kiechle FL and Zhang X: Apoptosis: biochemical aspects and clinical implications. Clin Chim Acta 326: 27-45, 2002.

6. Milbrandt J: A nerve growth factor-induced gene encodes a possible transcriptional regulatory factor. Science 238: 797-799, 1987.

7. Gashler A and Sukhatme VP: Early growth response protein 1 (Egr-1): prototype of a zinc-finger family of transcription factors. Prog Nucleic Acid Res Mol Biol 50: 191-224, 1995.

8. Fahmy RG and Khachigian LM: Antisense Egr-1 RNA driven by the CMV promoter is an inhibitor of vascular smooth muscle cell proliferation and regrowth after injury. J Cell Biochem 84 575-582, 2002

9. Rupprecht HD, Hoffer G, de Heer E, Sterzel RB, Faller G and Schoecklmann HO: Expression of the transcriptional regulator Egr-1 in experimental glomerulonephritis: requirement for mesangial cell proliferation. Kidney Int 51: 694-702, 1997.

10. Yan SF, Fujita T, Lu J, et al: Egr-1, a master switch coordinating upregulation of divergent gene families underlying ischemic stress. Nat Med 6: 1355-1361, 2000.

11. O'Donovan KJ, Tourtellotte WG, Millbrandt J and Baraban JM: The EGR family of transcription-regulatory factors: progress at the interface of molecular and systems neuroscience. Trends Neurosci 22: 167-173, 1999.

12. Lemaire P, Revelant O, Bravo R and Charnay P: Two mouse genes encoding potential transcription factors with identical DNA-binding domains are activated by growth factors in cultured cells. Proc Natl Acad Sci USA 85: 4691-4695, 1988.

13. Liu C, Yao J, de Belle I, Huang RP, Adamson E and Mercola D The transcription factor EGR-1 suppresses transformation of human fibrosarcoma HT1080 cells by coordinated induction of transforming growth factor- $\beta 1$, fibronectin, and plasminogen activator inhibitor-1. J Biol Chem 274: 4400-4411, 1999.

14. Liu C, Yao J, Mercola D and Adamson E: The transcription factor EGR-1 directly transactivates the fibronectin gene and enhances attachment of human glioblastoma cell line U251. J Biol Chem 275: 20315-20323, 2000.

15. Shareef MM, Cui N, Burikhanov R, et al: Role of tumor necrosis factor- $\alpha$ and TRAIL in high-dose radiation-induced bystander signaling in lung adenocarcinoma. Cancer Res 67: 11811-11820, 2007.

16. Huang RP, Fan Y, de Belle I, et al: Decreased Egr-1 expression in human, mouse and rat mammary cells and tissues correlates with tumor formation. Int J Cancer 72: 102-109, 1997.

17. Gitenay D and Baron VT: Is EGR1 a potential target for prostate cancer therapy? Future Oncol 5: 993-1003, 2009.

18. Riggs PK, Rho $\mathrm{O}$ and DiGiovanni J: Alteration of Egr-1 mRNA during multistage carcinogenesis in mouse skin. Mol Carcinog 27: 247-251, 2000.

19. Scharnhorst V, Menke AL, Attema J, et al: EGR-1 enhances tumor growth and modulates the effect of the Wilms' tumor 1 gene products on tumorigenicity. Oncogene 19: 791-800, 2000.

20. Eid MA, Kumar MV, Iczkowski KA, Bostwick DG and Tindall DJ: Expression of early growth response genes in human prostate cancer. Cancer Res 58: 2461-2468, 1998.
21. Arimochi H, Morita K, Kataoka K, Nakanishi S, Kuwahara T and Ohnishi Y: Suppressive effect of Clostridium perfringensproduced heat-stable substance(s) on proliferation of human colon adenocarcinoma HT29 cells in culture. Cancer Lett 241: 228-234, 2006

22. Chen A, Xu J and Johnson AC: Curcumin inhibits human colon cancer cell growth by suppressing gene expression of epidermal growth factor receptor through reducing the activity of the transcription factor Egr-1. Oncogene 25: 278-287, 2006.

23. Mahalingam D, Natoni A, Keane M, Samali A and Szegezdi E: Early growth response-1 is a regulator of DR5-induced apoptosis in colon cancer cells. Br J Cancer 102: 754-764, 2010.

24. Edge SB, Byrd DR, Compton CC, Fritz AG, Greene FL, Trotti A (eds): AJCC Cancer Staging Manual. 7th edition. Springer, New York, pp143-163, 2010.

25. Gavrieli Y, Sherman Y and Ben-Sasson SA: Identification of programmed cell death in situ via specific labeling of nuclear DNA fragmentation. J Cell Biol 119: 493-501, 1992.

26. Kobayashi D, Yamada M, Kamagata C, et al: Overexpression of early growth response-1 as a metastasis-regulatory factor in gastric cancer. Anticancer Res 22: 3963-3970, 2002.

27. Zheng L, Pu J, Jiang G, et al: Abnormal expression of early growth response 1 in gastric cancer: association with tumor invasion, metastasis and heparanase transcription. Pathol Int 60: 268-277, 2010.

28. McCormick D, Chong H, Hobbs C, Datta C and Hall PA: Detection of the Ki-67 antigen in fixed and wax-embedded sections with the monoclonal antibody MIB1. Histopathology 22: $355-360,1993$

29. Weidner N, Moore DH II and Vartanian R: Correlation of Ki-67 antigen expression with mitotic figure index and tumor grade in breast carcinomas using the novel 'paraffin'-reactive MIB1 antibody. Hum Pathol 25: 337-342, 1994.

30. Oka S, Uramoto H, Shimokawa H, Iwanami T and Tanaka F: The expression of Ki-67, but not proliferating cell nuclear antigen, predicts poor disease free survival in patients with adenocarcinoma of the lung. Anticancer Res 31: 4277-4282, 2011.

31. He WL, Li YH, Yang DJ, et al: Combined evaluation of centromere protein $\mathrm{H}$ and $\mathrm{Ki}-67$ as prognostic biomarker for patients with gastric carcinoma. Eur J Surg Oncol 39: 141-149, 2013.

32. Hilska M, Collan YU, O Laine VJ, et al: The significance of tumor markers for proliferation and apoptosis in predicting survival in colorectal cancer. Dis Colon Rectum 48: 2197-2208, 2005.

33. Sun T, Tian H, Feng YG, Zhu YQ and Zhang WQ: Egr-1 promotes cell proliferation and invasion by increasing $\beta$-catenin expression in gastric cancer. Dig Dis Sci 58: 423-430, 2013.

34. Kyrylkova K, Kyryachenko S, Leid M and Kioussi C: Detection of apoptosis by TUNEL assay. Methods Mol Biol 887: 41-47, 2012.

35. Lifshitz S, Lamprecht SA, Benharroch D, Prinsloo I, PolakCharcon S and Schwartz B: Apoptosis (programmed cell death) in colonic cells: from normal to transformed stage. Cancer Lett 163: 229-238, 2001

36. Sezer C, Yildirim M, Yildiz M, et al: Prognostic significance of biological apoptosis factors in gastric cancer. J BUON 18: 138-146, 2013.

37. Hernandez JM, Farma JM, Coppola D, et al: Expression of the antiapoptotic protein survivin in colon cancer. Clin Colorectal Cancer 10: 188-193, 2011.

38. Theodoropoulos GE, Gazouli M, Vaiopoulou A, et al: Polymorphisms of caspase 8 and caspase 9 gene and colorectal cancer susceptibility and prognosis. Int J Colorectal Dis 26 : 1113-1118, 2011. 